\title{
Distribution of the Invasive Caprellid Caprella scaura (Crustacea: Amphipoda) in Cádiz Marina, Southern Spain: Implications for its Dispersal
}

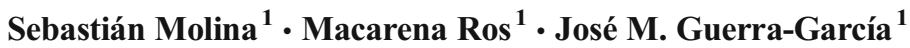

Published online: 24 May 2017

(C) Springer International Publishing Switzerland 2017

\begin{abstract}
The invasive caprellid Caprella scaura Templeton, 1836 is rapidly spreading along marinas of Southern Spain, becoming one of the dominant species of the macrofoulers associated to bryozoans and hydroids of communities in harbours. In order to explore the abundance and distribution patterns of the species in the different habitats available in marinas (floating pontoons, buoys and hull boats), a spatial study was conducted in Cádiz Marina (Puerto América) during two sampling periods (July and November). The bryozoan Bugula neritina was present in all the habitats and were selected as a substrate for comparison among habitats. In the floating pontoons, the single species C. scaura represented more than $60 \%$ of all the epifaunal individuals (including other crustaceans, polychaetes, molluscs and pycnogonids), both in July and November. In the boats and the buoys, C. scaura was dominant also in November, while gammarideans dominated in July. Abundance of C. scaura was significantly higher in floating pontoons than in hull boats. The attached caprellids to the boats are frequently exposed to strong water currents originated by boat displacements during local trips, so the results of the present study seem to indicate a preference of C. scaura by more stable substrates and non-exposed waters within the marina, such as floating pontoons.
\end{abstract}

Keywords Caprella scaura $\cdot$ Alien caprellid · Marina · Harbour · Spain

José M. Guerra-García jmguerra@us.es

1 Departamento de Zoología, Facultad de Biología, Universidad de Sevilla, Avda. Reina Mercedes 6, 41012 Sevilla, Spain

\section{Introduction}

Artificial constructions in coastal areas have recently attracted the attention of the scientific community due to their implication in the conservation of marine ecosystems (Megina et al. 2013). Marine bioinvasions are one of the greatest threats from human activity to ocean and coastal marine ecosystems (Carlton 1996; Ruiz et al. 2000) and watercraft, both commercial and recreational, are the main vectors for the introduction and distribution of invasive species, due to encrustation and subsequent dispersal from hulls, or from ballast water (Somaio et al. 2007). Alien species transported by international ships must find adequate substrates on which to live where they are introduced and the urban structures associated with ports and marinas may frequently provide these substrates (Rocha et al. 2010). Therefore, marinas can be both the first entry point for non-natives via international yachts and they can act to provide a network and reservoirs of suitable habitats for the secondary spread of a species via domestic yachting activity (Ashton et al. 2006). Marinas have been described as "sheltered islands" for marine alien organisms (Bax et al. 2002) and floating pontoons of the marinas represent substantial artificial habitats for marine organisms (Connell 2000). At marinas, the immersed parts of the floating pontoons are not usually treated with antifouling coatings and so can develop extensive plant and invertebrate growths (Minchin 2007). This is particularly important in the case of small invertebrates, like caprellid amphipods, because marinas' fouling communities include arborescent substrates such as bryozoans or hydroids which may act as habitat for caprellids introduced via recreational boating (Ros et al. 2013a; Ros and GuerraGarcía 2012). In spite of having direct development, caprellids are able to disperse large distances associated with detached aquaculture buoys and other artificial substrates ("rafting") or as a part of the fouling communities of ships and boats (Thiel 
et al. 2003). Biogenic substrates which form the fouling communities are usually colonizing the sumerged parts of the floating pontoons, buoys, ropes, surface of boats, etc. along the whole marina, and abundant epiphytic fauna inhabit these substrates in very high densities.

Caprella scaura was found to be established in marinas of Southern Spain (Guerra-García et al. 2011a). This species was described from Mauritius and later reported from several regions of the world (see Ros et al. 2014). The species was first recorded in the Iberian Peninsula in 2005 (Martínez and Adarraga 2008) at the coast of Gerona (northeastern coast of Spain), and in southern Spain in 2010 at the coast of Cádiz. In fact, $C$. scaura is now the dominant caprellid species along marinas of Southern Iberian Peninsula, with ovigerous females and juveniles throughout the whole year (Ros et al. 2013a). Although the abundance and seasonal fluctuations of $C$. scaura have been studied in Southern Spain there is no information available about the small scale distribution in the different habitats inside the marina. The species is associated to substrates (mainly bryozoans) attached to the floating pontoons, but it can be found also in similar substrates attached to hull boats or buoys. Taking into account that C. scaura inhabits the marina of Cádiz during the whole year, it is interesting to find out if the species inhabits indistinctly all the habitats or show preferences by some of them. Consequently, the main objective of the present study is to explore the abundance and distribution patterns of Caprella scaura at the different habitats available in the marina (hull boats, floating pontoons and buoys) to properly understand the invasive potential and spread of the species.

\section{Material and Methods}

The study was conducted in a recreational boating marina, Puerto América Cádiz Marina, located on the Atlantic coast of Southern Spain $\left(36^{\circ} 32^{\prime} 29^{\prime \prime} \mathrm{N}, 6^{\circ} 17^{\prime}\right.$ $61^{\prime \prime} \mathrm{W}$ ) (Fig. 1). Two surveys were carried out, one in 10 July 2012 (coinciding with the dry and warm season) and another one in 17 November 2012 (wet and colder season). Water salinity and temperature were measured using a conductivity meter WTW Cond $340 \mathrm{i} / \mathrm{SET}$. Five measures were taken along the marina in each season.

To properly compare among habitats, the same substrate in pontoons, hull boats and buoys, were collected. We selected the bryozoan Bugula neritina (L.) based on: (1) this substrate is present in the three habitats selected, (2) it is one of the dominant substrates in marinas across the world, (3) it is present along the whole year in the studied area, (4) many other studies focused on amphipod communities have used this substrate so comparisons could be done (see e.g. Conradi

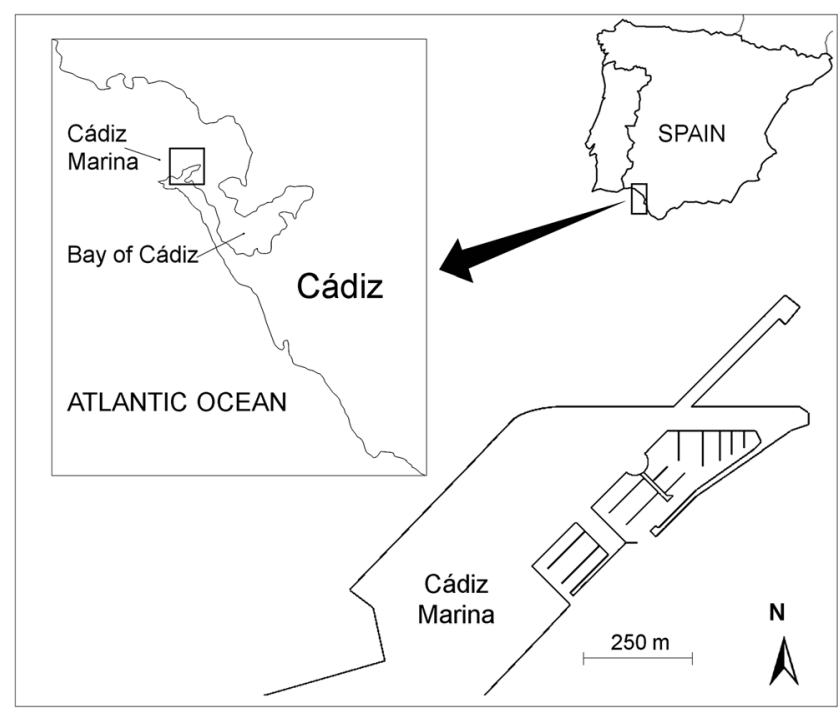

Fig. 1 Study area showing the location of Cádiz Marina at the Atlantic coast of Southern Spain

et al. 1997) and (5) it is considered as one of the preferred substrate for C. scaura in the invaded area (Ros et al. 2013a).

During each survey (July and November 2012), nine replicates per substrate were collected in each habitat (pontoons, boats and buoys) (Fig. 2). Each replicate consisted of a colony of $B$. neritina randomly collected inside the harbour, separated by tens-hundreds of metres. All samples were directly removed by hand from the lateral surface of the floating pontoons, the submerged surface of the buoys, or the hull of the boats (mainly small local yachts), and preserved in $80 \%$ ethanol. Floating pontoons consisted of plastic material with a wooden boardwalk.

In the laboratory, all the associated macrofaunal organisms were sorted from each sample and caprellids were identified to species level. Volume of the each sample of $B$. neritina was estimated as the difference between the initial and final volume when placed into a graduated narrow cylinder with a fixed amount of water. Dry weight was also measured after desiccating the samples at $70{ }^{\circ} \mathrm{C}$ during $24 \mathrm{~h}$.

Differences in temperature and salinity between July and November were analysed using one-way ANOVA, provided that data were normally distributed (Kolmogorov-Smirnov test) and variances homogeneous (Cochran's C-test). The influence of habitat and season (July vs November) on the volume of the B. neritina colonies and the abundance of Caprella scaura was tested using two-way ANOVA with the following factors: 'Habitat', a fixed factor, with three levels: pontoons, hull boats and buoys, and 'Season', a fixed factor and orthogonal with 'Habitat', with 2 levels: dry and warm season (July 2012) and wet and colder season 
Fig. 2 Habitats considered: (a) floating pontoons; (b) buoys; (c) hull boats; (d) male specimen of C. scaura attached to the fouling community of the floating pontoon
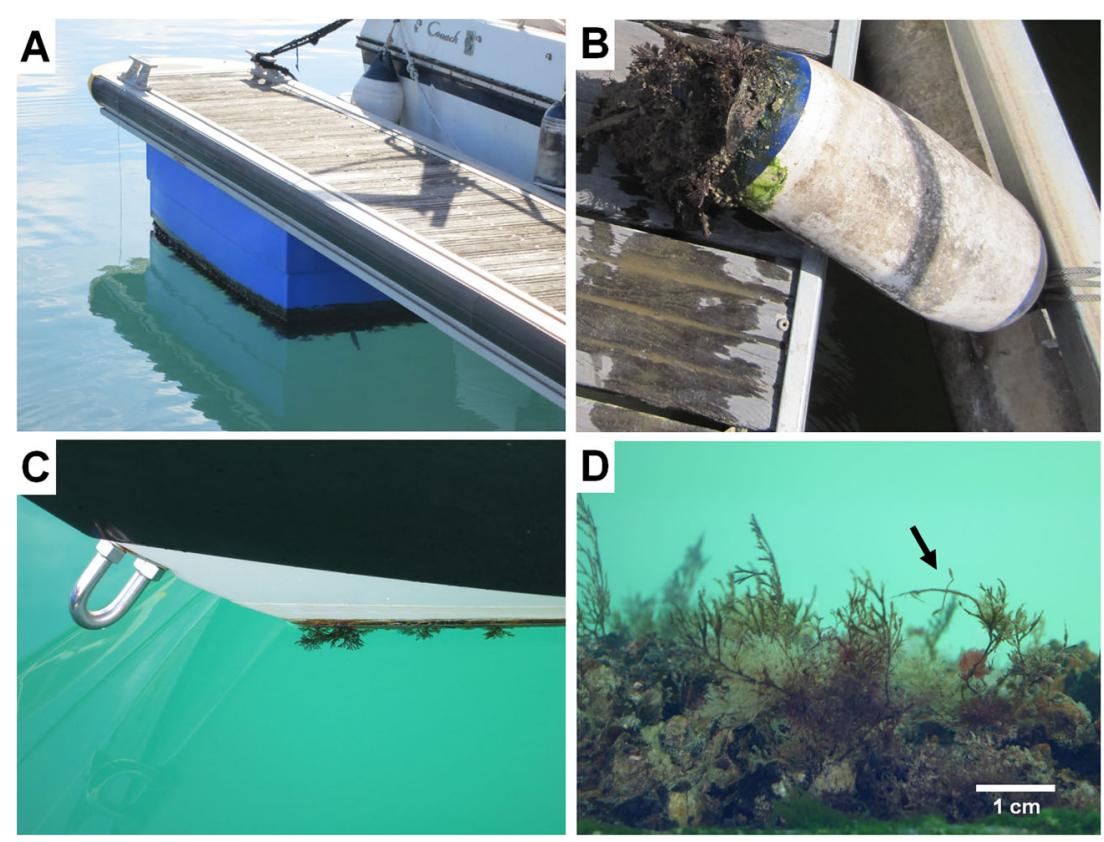

(Nov 2012). Prior to ANOVA, heterogeneity of variances was tested with Cochran's C-test. When ANOVA indicated a significant difference for a given factor, the source of difference was identified by applying the Student-Newman-Keul (SNK) test (Underwood 1997). Analyses were carried out using the SPSS program and GMAV5 (Underwood and Chapman 1998).

\section{Results and Discussion}

Water temperature was significantly higher in July $\left(23.2 \pm 0.5{ }^{\circ} \mathrm{C}\right.$, Mean $\left.\pm \mathrm{SD}\right)$ than November $\left(17.2 \pm 0.5{ }^{\circ} \mathrm{C}\right)$ (one way-ANOVA, $\mathrm{F}=15,664.5$, $p<0.001)$. Salinity was also higher in July $(38.6 \pm 0.1 \mathrm{psu})$ than November $(35.7 \pm 0.1 \mathrm{psu})$ (one way-ANOVA, $\mathrm{F}=315.3, p<0.001$ ) (Fig. 3). This is the general pattern which can be measured in Cádiz Marina, higher water temperatures and salinities in summer and lower values in winter, after the rainy season (Ros et al. 2013a). A similar trend is also obtained in natural environments of Southern Spain (Guerra-García et al. 2011b); salinity decrease after the rains of September and October, being November usually the rainiest month of the year in the area.

Differences in the environmental data were probably affecting to the development of the colonies of Bugula neritina, which reached a higher size (measured as a higher volume) in July in the three habitats (Fig. 4,
Fig. 3 Water temperature $\left({ }^{\circ} \mathrm{C}\right)$ and salinity (psu) measured in July and November in the study area. Values are mean \pm standard deviation

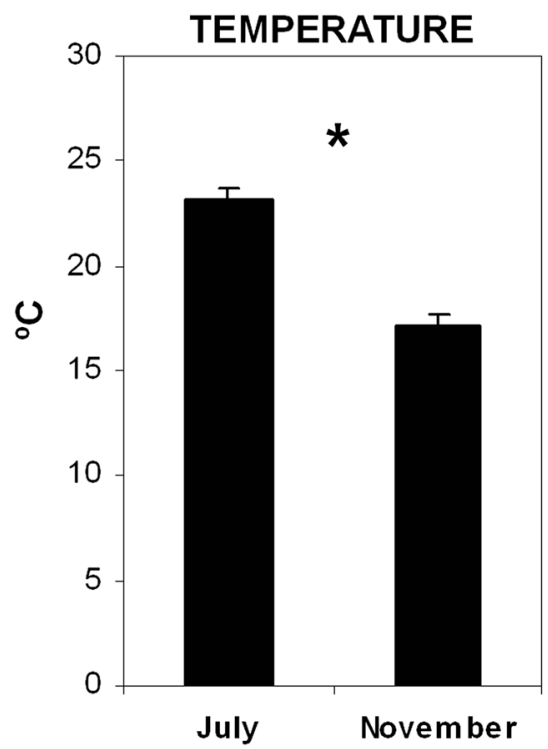

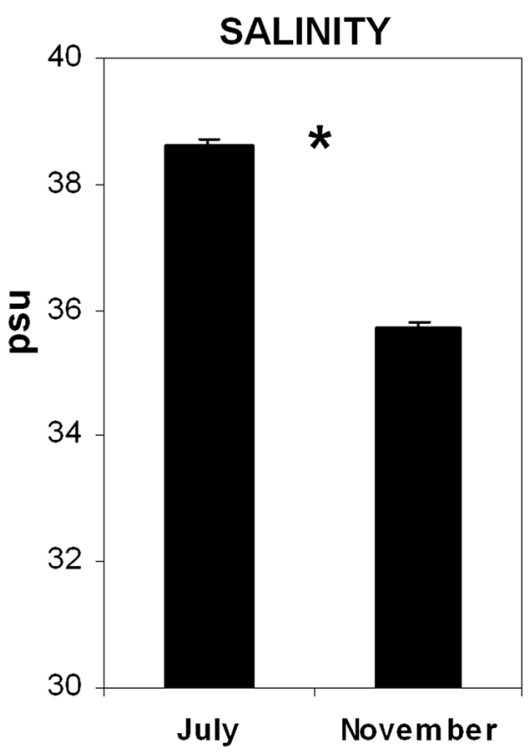




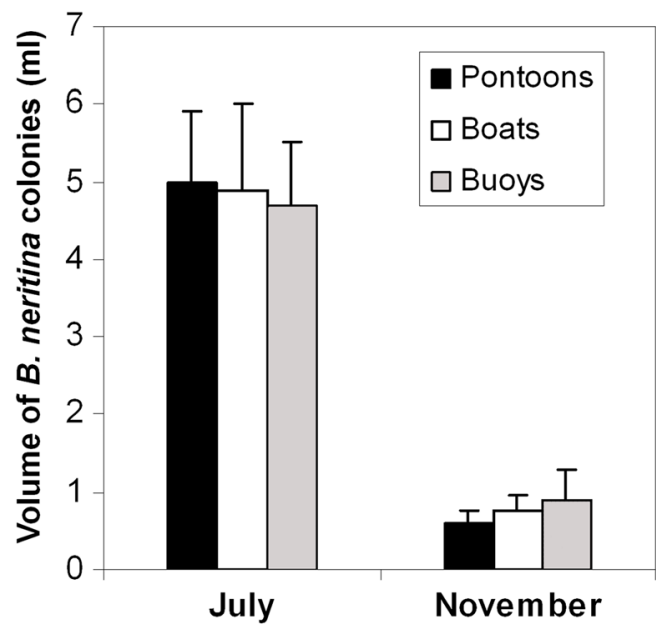

Fig. 4 Volume $(\mathrm{ml})$ of $B$. neritina colonies collected in July and November for each habitat. Values are mean \pm standard deviation $(n=9$ for each habitat and month)

Table 1). In November, the colonies were significantly smaller than in July, and the pattern was the same in pontoons, boats and buoys. Ros et al. (2013a) also reported the highest percentage frecuency of Bugula neritina in summer months, and Conradi (1995) also found the maximum sizes of the colonies from June to September. On the other hand, the volume of the colonies were significantly correlated with the biomass (dry weight) $(r=0.94$, $p<0.001)$.

Regarding the macrofaunal community, the only caprellid present in the samples was Caprella scaura. It is remarkable that this species represented more than the half of all the macrofauna specimens which were sorted and counted (Fig. 5). Both, in July and November, crustaceans were the most important group, with more than $90 \%$ of the abundance percentage. The other groups such as annelids and molluscs were scarcely represented, always with less than $10 \%$. Within the crustaceans, amphipods were dominant, followed by isopods and tanaids (Fig. 5).

Table 1 Results of the two-way ANOVA for volume ( $\mathrm{ml})$ of $B$. neritina samples and density of Caprella scaura (individuals $/ 1000 \mathrm{ml}$ B. neritina) among habits (pontoons vs boats vs buoys) and season (July vs November)

Sample volume (ml) Density of Caprella scaura

\begin{tabular}{llllllll}
\hline $\begin{array}{c}\text { Source of } \\
\text { variation }\end{array}$ & df & MS & $F$ & $P$ & MS & $F$ & $P$ \\
$\begin{array}{l}\text { Habitat } \\
\quad 2\end{array}$ & 1.07 & 0.3 & 0.7260 & $6,125,257.4$ & 3.5 & $0.0380^{*}$ \\
$\quad$ Ha) & & & & & & & \\
Season (Se) & 1 & 264.67 & 80.0 & $0.0001 * * *$ & $4,890,955.8$ & 6.3 & $0.0152^{*}$ \\
Ha X Se & 2 & 3.31 & 1.0 & 0.375 & $2,038,863.6$ & 1.6 & 0.1970 \\
Residual & 48 & 158.76 & & & $4,980,748.2$ & & \\
\hline
\end{tabular}

$M S$ mean square, $d f$ degrees of freedom. ${ }^{*} p<0.05, * * * p<0.001$

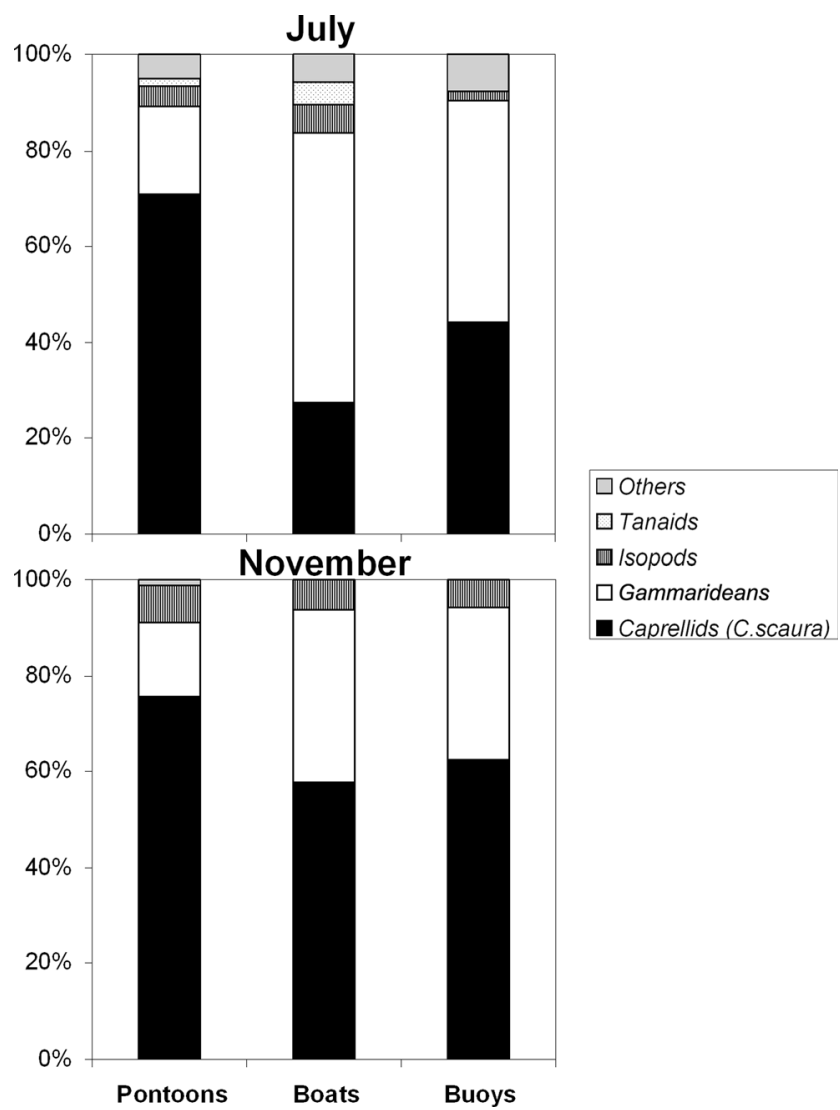

Fig. 5 Abundance percentage of $C$. scaura in comparison with other groups of associated macrofauna to $B$. neritina, such as gammarideans, isopods and tanaids. Others include polychaetes, molluscs and pycnogonids

In the floating pontoons, the single species $C$. scaura represented more than $60 \%$ of all the macrofaunal individuals, both in July and November. In the boats and the buoys, C. scaura was dominant also in November, while gammarids reached the highest abundances in July.

The two-way ANOVA showed significant differences of Caprella scaura density (measured as individuals/ $1000 \mathrm{ml} \mathrm{B.} \mathrm{neritina)} \mathrm{between} \mathrm{sampling} \mathrm{times} \mathrm{(with} \mathrm{the}$ highest densities being measured in November) and among habitats (Fig. 6, Table 1). The SNK test showed that density values in the pontoons were significantly higher than in the other two habitats $(p<0.05)$. Although the absolute number of specimens counted in July and November were rather similar, significant differences were measured in the number of individuals per $1000 \mathrm{ml}$ of $B$. neritina between the two months. This is probably due to the small size of the colonies in November which involves less substrate offered to the caprellids, and consequently the individuals are more crowed in the same colony of substrate. We could hypothesise that the highest densities of C. scaura in November could negatively affect to the gammaridean 


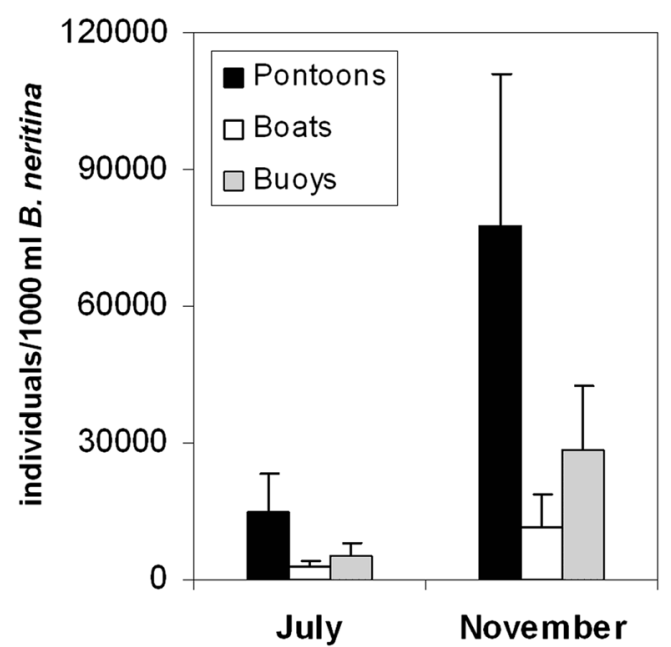

Fig. 6 Abundance of C. scaura (ind/1000 $\mathrm{ml} \mathrm{B.} \mathrm{neritina)} \mathrm{in} \mathrm{July} \mathrm{and}$ November for each habitat. Values are mean \pm standard error of the mean ( $n=9$ for each habitat and month)

abundances which decrease in November, probably related to competition process. These potential interactions should be tested in the future based on experimental studies under controlled conditions.

The present study reflects a consistent pattern, both in July and November, of higher abundances of C. scaura measured in pontoons, and lower densities in buoys and especially hull boats. Taking into account that we selected the same substrate ( $B$. neritina) in the same marina, and that the colonies collected were of the same size in the three habitats within each month (Fig. 4), the differences should be explained on the basis of habitat differences. Floating pontoons are fixed and more stable substrates than boats and buoys (which are anchored to the boats). The boats are local yachts which make frequent trips to nearby areas, so the attached caprellids to the hull boats are frequently exposed to strong water currents originated by the displacements of the boats. Consequently, floating pontoons could act as a reservoir of caprellids and mooring buoys may act as stepping stones between the hull boats and the artificial structures that constitute the marina, including floating pontoons (Fig. 7). According to the data obtained in the present study (significant higher densities of the invasive caprellid in floating pontoons, both in July and November), it seems that only a reduced fraction of the "reservoir population" of C. scaura is susceptible to be dispersed by recreational boats. Furthermore, if the responsible of this distribution is the hydrodynamics, it is probable that the population dispersed will suffer another reduction in its number of individuals after ship transit from the donor marina to the recipient marina. These observations supports the general trend of the observed preference of non-native caprellids (C. scaura and P. pusilla, the two only introduced caprellids so far in the Iberian Peninsula and the Mediterranean) by marinas with low hydrodynamics being absent in adjacent exposed rocky shores (Ros et al. 2013b). In North America, the majority of non-native species occur at sheltered waters of bays and estuaries with a smaller number reported on more exposed areas of outer coastal habitats (Ruiz et al. 2009). Future experimental designs in the field and in laboratory conditions are needed to properly address if the invasive caprellids prefer shelter habitats and avoid exposed habitats. This topic has not received enough attention in previous studies and a detailed study of these preferences is very important to understand the invasion process.
Fig. 7 Schematic representation of the distribution model of Caprella scaura (Cs) associated with Bugula neritina $(\mathrm{Bn})$ within a recreational marina and its possible implication in its invasion dynamic. FP: Floating pontoons, MB: mooring buoys, HB: hull boats

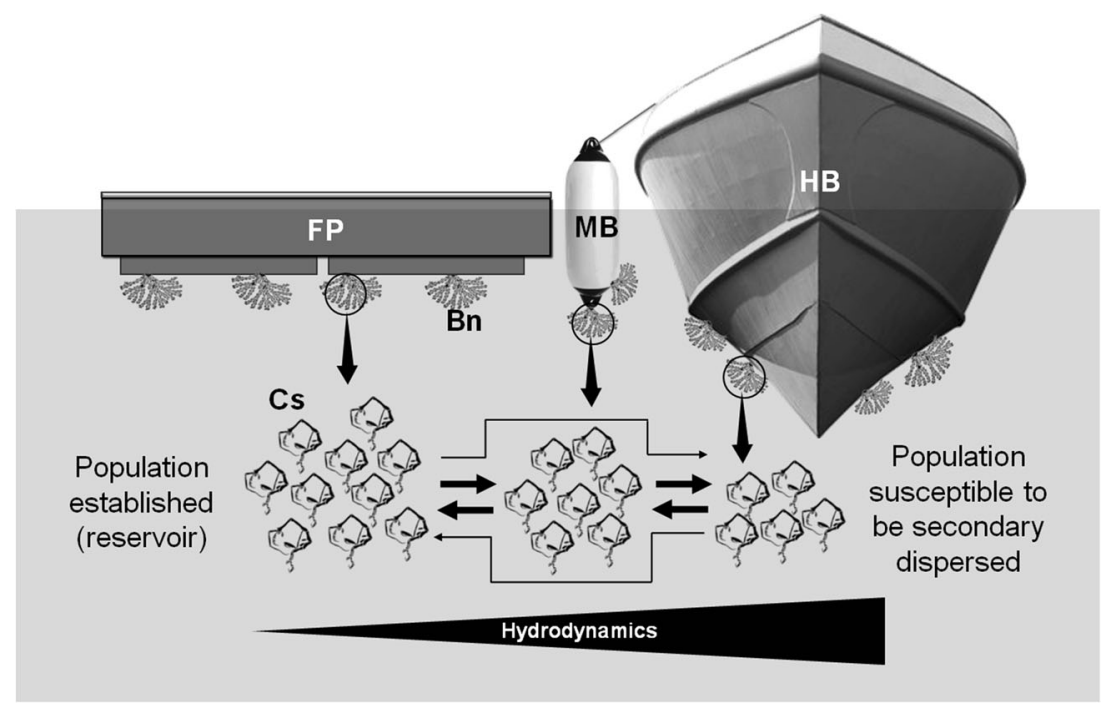


Acknowledgements This study constituted the final degree project in Biology of the first author (SM). Financial support of this work was provided by the the Ministerio de Economía y Competitividad (Project CGL2011-22474, internal reference 2011-707) co-financed by the ERDF, European Union, and by the Consejería de Economía, Innovación, Ciencia y Empleo, Junta de Andalucía (Project P11-RNM-7041). We also wish to thank the staff of the Cádiz Marina for their courtesy in allowing us to use their facilities. Thanks are also due to two anonymous reviewers for valuable comments to improve the manuscript.

\section{References}

Ashton G, Boos K, Shucksmith R, Cook E (2006) Rapid assessment of the distribution of marine non-native species in marinas in Scotland. Aquat Invasions 1:209-213

Bax N, Hayes K, Marshall A, Parry D, Thresher R (2002) Man-made marinas as sheltered islands for alien marine organisms: establishment and eradication of an alien invasive marine species. In: Veitch CR, Clout MN (eds) Turning the tide: the eradication of invasive species. IUCN SSC Invasive Species Specialist Group. IUCN Gland, Switzerland and Cambridge

Carlton JT (1996) Marine bioinvasions: the alternation of marine ecosystems by nonindigenous species. Oceanography 9:36-43

Connell SD (2000) Floating pontoons create novel habitats for subtidal epibiota. J Exp Mar Biol Ecol 247:183-194

Conradi M (1995) Distribución espaciotemporal de los peracáridos (Crustacea) asociados a Bugula neritina (L, 1758) en la bahía de Algeciras. Tesis Doctoral, Universidad de Sevilla, Sevilla, Aspectos faunísticos y zoogeográficos, $210 \mathrm{pp}$

Conradi M, López-González PJ, García-Gómez JC (1997) The amphipod community as a bioindicator in Algeciras Bay (southern Iberian Peninsula) based on a spatio-temporal distribution. PSZN Marine Ecology 18:97-111

Guerra-García JM, Ros M, Dugo-Cota A, Burgos V, Flores-León AM, Baeza-Rojano E, Cabezas MP, Núñez J (2011a) Geographical expansion of the invader Caprella scaura (Crustacea: Amphipoda: Caprellidae) to teh East Atlantic coast. Mar Biol 158:2617-2622

Guerra-García JM, Baeza-Rojano E, Cabezas MP, García-Gómez JC (2011b) Vertical distribution and seasonality of peracarid crustaceans associated with intertidal macroalgae. J Sea Res 65:256-264

Martínez J, Adarraga I (2008) First record of invasive caprellid Caprella scaura Templeton, 1836 sensu lato (Crustacea: Amphipoda: Caprellidae) from the Iberian Peninsula. Aquat Invasions 3:165-171
Megina C, González-Duarte MG, López-González PJ, Piraino S (2013) Harbours as marine hábitats: hydroid assemblages on sea-walls compared with natural habitats. Mar Biol 160:371-381

Minchin D (2007) Rapid coastal survey for targeted alien species associated with floating pontoons in Irelanda. Aquat Invasions 2:63-70

Rocha RM, Cangussu LC, Braga MP (2010) Stationary substrates facilitate bioinvasion in Paranaguá Bay in southern Brazil. Braz J Oceanogr 58:23-28

Ros M, Guerra-García JM (2012) On the occurrence of the tropical caprellid Paracaprella pusilla Mayer, 1890 (Crustacea: Amphipoda) in Europe. Mediterr Mar Sci 13:134-139

Ros M, Guerra-García JM, González-Macias M, Saavedra A, López-Fe CM (2013a) Influence of fouling communities on the establishment success of alien caprellids (Crustacea: Amphipoda) in southern Spain. Mar Biol Res 9:293-305

Ros M, Vázquez-Luis M, Guerra-García JM (2013b) The role of marinas and recreational boating in the occurrence and distribution of exotic caprellids (Crustacea: Amphipoda) in the western Mediterranean: Mallorca Island as a case study. J Sea Res 83:94-108

Ros M, Guerra-García JM, Navarro-Barranco C, Cabezas MP, VázquezLuis M (2014) The spreading of the non-native caprellid (Crustacea: Amphipoda) Caprella scaura Templeton, 1836 into southern Europe and northern Africa: a complicated taxonomic history. Mediterr Mar Sci 15:94-108

Ruiz GM, Fofonoff PW, Carlton JT, Wonham MJ, Hines AH (2000) Invasion of coastal marine communities in North America: apparent patterns, processes and biases. Annu Rev Ecol Evol Syst 31:481-531

Ruiz GM, Freestone AL, Fofonoff PW, Simkanin C (2009) Habitat distribution and heterogeneity in marine invasion dynamics: the importance of hard substrate and artificial structure. In: Wahl M (ed) Marine hard bottom communities: patterns, dynamics. Diversity and Change. Springer, Heidelberg, pp 321-332

Somaio NC, Moreira RR, Bettini PF, Roper JJ (2007) Use of artificial substrata by introduced and cryptogenic marine species in Paranaguá Bay, southern Brazil. Biofouling 23:319-330

Thiel M, Guerra-García JM, Lancellotti DA, Vásquez N (2003) The distribution of littoral caprellids (Crustacea: Amphipoda: Caprellidea) along the Pacific coast of continental Chile. Rev Chil Hist Nat 76:203-218

Underwood AJ (1997) Experiments in Ecology: their logical design and interpretation using analysis of variance. Cambridge University Press, UK, 524 pp

Underwood AJ, Chapman MG (1998) GMAV5 for windows: an analysis of variance program. University of Sydney, Institute of Marine Ecology 